International Journal of Veterinary Health Science \& Research (IJVHSR)

ISSN 2332-2748

\title{
A Study of the Effect of Vitamin C and Ocimum Sanctum Supplementation on Antioxidant Enzyme Levels in Broilers Under Heat-Stress
}

Research Article

\author{
L.S.S.Varaprasad Reddy ${ }^{1 *}$,V.Leela ${ }^{2}$, B.Sudhakara Reddy ${ }^{3}$, P.Ananda Reddy ${ }^{4}$ \\ ${ }^{1}$ Assistant Professor, Dept. of Veterinary Physiology, Sri Venkateswara Veterinary University, Y.S.R.District, Andhra Pradesh, India. \\ ${ }^{2}$ Professor, Dept. of Veterinary Physiology, Madras Veterinary College, Chennai, Tamil Nadu, India \\ ${ }^{3}$ Assistant Professor (Veterinary Medicine), Teaching Veterinary Clinical Complex, Sri Venkateswara Veterinary University, Y.S.R.District, \\ Andhra Pradesh, India. \\ ${ }^{4}$ Associate Professor \& Head, Dept. of Poultry Science, Sri Venkateswara Veterinary University, Y.S.R.District, Andhra Pradesh, India.
}

\section{Abstract}

\begin{abstract}
This experiment was conducted in heat-stressed broiler chicken to evaluate the effect of dietary supplementation of Vitamin C and Ocimum sanctum on antioxidative enzyme levels. A total of forty broiler chickens of day old age were divided into 4 groups of 10 each, were used for this study. Vitamin C (300 mg/kg), Ocimum sanctum leaf powder $(0.5 \%)$ and their combination were added to the basal diet. Superoxide dismutase (SOD), glutathione peroxidase (GSH-px), catalase, reduced glutathione (GSH) and lipid peroxidation levels in plasma were measured at the end of 6 weeks of age. Dietary supplementation of Vitamin C itself increased SOD, GSH-px, catalase enzyme levels significantly $(\mathrm{p}<0.05)$. However, supplementation of both Vitamin $\mathrm{C}$ and Ocimum sanctum effectively enhanced the levels of SOD, GSH-px, catalase, and GSH with concomitant decrease in lipid peroxidation levels in plasma. It is concluded that dietary supplementation of Vitamin C and its combination with Ocimum sanctum at $0.5 \%$ level can combat oxidative stress caused by high environmental temperature in broilers, by enhancing antioxidative enzyme levels.
\end{abstract}

Key Words: Antioxidants; Vitamin C; Ocimum sanctum; SOD; GSH-Px; Catalase; GSH; Lipid Peroxidation; Broiler Chickens.

\section{*Corresponding Author:}

L.S.S.Varaprasad Reddy,

Assistant Professor (Veterinary Medicine), Teaching Veterinary Clinical Complex, Sri Venkateswara Veterinary University, Proddatur, Y.S.R.District, Andhra Pradesh, India.

E-mail: shivavet@gmail.com

Recieved: May 20, 2014

Accepted: May 29, 2014

Published: May 31, 2014

Citation: L.S.S.Varaprasad Reddy, V.Leela, B.Sudhakara Reddy, P.Ananda Reddy. (2014). A Study of the Effect of Vitamin C and Ocimum Sanctum Supplementation on Antioxidant Enzyme Levels in Broilers Under Heat-Stress, Int J Vet Health Sci Res, 02(02), 21-23. doi: http://dx.doi. org/10.19070/2332-2748-140006

Copyright: L.S.S.Varaprasad $\operatorname{Reddy}^{\mathcal{O}} 2014$ This is an open-access article distributed under the terms of the Creative Commons Attribution License, which permits unrestricted use, distribution and reproduction in any medium, provided the original author and source are credited.

\section{Introduction}

Poultry production suffers significant losses because of heat stress. Heat stress adversely affects broiler performance and livability. Body temperature and metabolism rate of birds are relatively high compared to mammals, which make birds vulnerable to oxidative stress under high environmental temperature, which is the major cause of sudden death syndrome [1]. Heat stress not only adversely affects production performance but also increases the incidence of infectious and metabolic diseases in poultry. This can be minimizes by the use of anti-stress compounds. Antioxidants are substances, present biologically lower concentra- tions and significantly delay or prevent oxidation of substances like protein, lipids, DNA and carbohydrates [2]. External sources of antioxidant are essential for the control of oxidation process, which include vitamin C \& E, carotenoids, phytoflavanoids etc.

Vitamin C also commonly known as ascorbic acid is an important antioxidant. Although birds synthesize vitamin $\mathrm{C}$ in their body, however, its supplementation in the poultry diet has been recommended during stressful conditions [3]. Several herbal plants are found to posses anti oxidant properties and the ubiquitous herb i.e., Ocimum sanctum which belongs to Lamiaceae family is a fairly economic therapeutic agent for several pathological conditions as well as anti-stress [4] and antioxidant agent [5].

The present study was conducted to evaluate the effect of Vitamin $\mathrm{C}$ and Ocimum sanctum on antioxidant enzyme levels in broiler chicken under heat stress.

\section{Materials and Methods}

A forty broiler chicks of day old age were randomly divided into 4 groups comprising of 10 birds in each group with following dietary regimes.

Group I: Standard diet (Control)

Group II: Standard diet + Vitamin C (300mg/ kg)

Group III: Standard diet + Ocimum sanctum $(0.5 \%)$

Group IV: Standard diet + Vitamin C $(300 \mathrm{mg} / \mathrm{kg})+$ Ocimum sanctum $(0.5 \%)$

The birds were reared from day old to $6^{\text {th }}$ week of age in cages under standard managemental practices during months of April \& May. The temperature inside the house is ranged from 35 $38^{\circ} \mathrm{C}$. Freshly collected $O$. sanctum leaves were shade dried and powdered. Vitamin $C$ and Ocimum sanctum leaf powder were sup- 
plemented as above to the standard broiler diet. The broiler starter and finisher diets were fed ad libitum to the birds. The Ocimum sanctum leaf powders were used at $0.5 \%$ level of inclusion based on the reports of [6], along with Vitamin C (300 mg/kg).

Blood samples were collected at the end of $6^{\text {th }}$ week from the wing vein using heparinised vacutainer for separating plasma by standard procedures of centrifugation. The levels of superoxide dismutase (SOD) activity in plasma was measured by the method of [7], glutathione peroxidase (GSH-Px) activity as per the method described by [8] and catalase activity as per the method of [9]. Reduced glutathione levels in plasma were estimated by the method of [10]. Lipid peroxidation assay was carried out according to [11]. Statistical analysis of the data was analyzed by randomized block design as per [12].

\section{Results \& Discussion}

Superoxide dismutase is considered as critical antioxidative enzyme that acts as a scavenger of oxygen anion to form hydrogen peroxide and hence diminishes the toxic effects due to the free radical. This primary defense widely distributed in oxygen metabolizing cells to protect aerobic cells from deleterious actions of free radicals [13]. The mean plasma SOD values of broilers at 6 weeks of age as influenced by dietary supplementation of Vitamin C and O. sanctum, is presented in Table 1. In the present study, dietary supplementation of Vitamin C $(300 \mathrm{mg} / \mathrm{kg})$, O. sanctum at $0.5 \%$ level and their combination significantly $(\mathrm{p}<0.05)$ enhanced plasma SOD activity when compared control group. The results of our study are in accordance with the earlier reports of [14], who observed that SOD activity significantly $(\mathrm{P}<0.05)$ increased with dietary supplementation of Vitamin $C$ in summer stressed broilers. Similarly, [6] reported significant $(\mathrm{P}<0.05)$ increase in SOD activity with dietary supplementation of O. sanctum in broilers.

The Glutathione peroxidase, present in the cytosol and mitochondria matrix, catalyses the degradation of various peroxides by sacrificial oxidation of glutathione. Glutathione peroxidase enzyme reduces peroxides and protects cells against the damaging effects of oxidation. The mean plasma GSH-Px values of broiler chickens at 6 week of age as influenced by dietary supplementation of Vitamin C and O. sanctum is presented in Table 1.

In the present study, there is a significant increase in plasma GSHPx activity with Vitamin $C$ supplementation and its combination with of O. sanctum at $0.5 \%$ level. Similar findings were observed by [6], that oxidative stress was effectively inhibited by the dietary supplementation of $O$. sanctum and selenium by increasing plasma GSH-Px activity in broiler chicken.

The catalase causes the reduction reaction of hydrogen peroxides and protects the tissues from highly reactive hydroxyl radicals.
During stress the accumulated free radicals causes the inactivation of this enzyme by simple glycation which reduces structural abnormality and thus limits the activity of catalase [11]. The mean plasma catalase values of broiler chickens of 6 weeks of age, influenced by dietary supplementation of Vitamin $\mathrm{C}$ and $O$. sanctum are presented in Table 1 .

In the present study, catalase activity was highest with Vitamin C supplemented with $O$. sanctum followed by Vitamin C supplemented alone and $O$. sanctum alone supplemented group when compared to control group. The enhanced catalase activity in the group with combination of Vitamin $\mathrm{C}$ and Ocimum sanctum indicates synergistic effect of Vitamin $\mathrm{C}$ and $O$. sanctum on scavenging free radicals and hydrogen peroxides.

The findings of increased plasma catalase levels in the present study were in agreement with the reports of [6], they observed increases in plasma catalase enzyme levels by supplementation of O. sanctum in broilers. Similarly, [14] reported that catalase activity significantly $(\mathrm{P}<0.05)$ increased with dietary supplementation of Vitamin $\mathrm{C}$ in summer stressed broilers.

GSH (reduced glutathione) offers protection against oxygen derived free radicals and cellular lethality following exposure to oxidative stress. Its high electron donating capacity combined with higher intracellular concentrations generate great reducing power [15]. Dietary supplementation of Vitamin C and O. sanctum and their combinations on plasma GSH levels is presented in Table 2.

The findings of increased plasma GSH (reduced glutathione) levels in the present study were in agreement with the reports of [16], they observed increases in plasma GSH enzyme levels by supplementation of $O$. sanctum in broilers.

Lipid peroxidation occurs as a consequence of increased oxidative stress primarily due to disruption of pro-oxidant/antioxidant balance. Increased oxidative stress has been associated with increased lipid peroxidation in many diseases [17]. In the present study, plasma malondialdehyde (MDA) levels were decreased with dietary supplementation of Vitamin $\mathrm{C}$ and Ocimum sanctum. This may be due to conversion of lipid peroxides to alcohol derivatives rather than MDA in the presence of higher GSH levels with Vitamin $\mathrm{C}$ and Ocimum sanctum.

The findings of decreased plasma malondialdehyde (MDA) levels in the present study were in agreement with the reports of (14), they observed decreased plasma malondialdehyde (MDA) levels by supplementation of Vitamin C in broilers. Similarly, [18] observed that there was significant decrease in plasma malondialdehyde (MDA) levels by supplementation of Vitamin $\mathrm{C}$ in broilers. [16] observed that there was significant decrease in plasma malondialdehyde (MDA) levels by supplementation of Ocimum sanctum

Table 1. Effect of dietary supplementation of Vitamin C, Ocimum sanctum and their combinations on SOD, GSH-Px and Catalase enzyme levels in broilers.

\begin{tabular}{|l|l|l|l|}
\hline Groups & $\begin{array}{l}\text { SOD }(\mathbf{5 0} \% \text { pyrogyllol } \\
\text { auto-oxidation/ } \mathbf{m i n} / \mathbf{m g})\end{array}$ & $\begin{array}{l}\text { GSH-Px }(\boldsymbol{\mu M} \text { of GSH } \\
\text { utilized/ } \mathbf{m i n} / \mathbf{m g})\end{array}$ & $\begin{array}{l}\text { Catalase }\left(\boldsymbol{\mu M} \text { of } \mathbf{H}_{2} \mathbf{O}_{2}\right. \\
\text { decomposed } / \mathbf{m i n} / \mathbf{m g})\end{array}$ \\
\hline I & $2.23^{\mathrm{a}} \pm 0.03$ & $2.46^{\mathrm{a}} \pm 0.01$ & $41.79^{\mathrm{a}} \pm 0.11$ \\
\hline II & $2.85^{\mathrm{c}} \pm 0.02$ & $2.88^{\mathrm{b}} \pm 0.02$ & $44.54^{\mathrm{c}} \pm 0.18$ \\
\hline III & $2.64^{\mathrm{b}} \pm 0.03$ & $2.85^{\mathrm{b}} \pm 0.02$ & $43.87^{\mathrm{b}} \pm 0.07$ \\
\hline IV & $3.15^{\mathrm{d}} \pm 0.02$ & $3.28^{\mathrm{c}} \pm 0.01$ & $45.15^{\mathrm{d}} \pm 0.09$ \\
\hline
\end{tabular}

Means bearing common superscripts in column do not differ significantly $(\mathrm{p}<0.05)$ 
Table 2. Effect of dietary supplementation of Vitamin C, Ocimum sanctum and their combinations on Reduced glutathione and Lipid peroxidation levels in broilers.

\begin{tabular}{|l|l|l|}
\hline Groups & $\begin{array}{l}\text { Reduced glutathione (mg } \\
\text { GSH / ml) }\end{array}$ & $\begin{array}{l}\text { Lipid peroxidation } \\
\text { (nM of MDA / ml) }\end{array}$ \\
\hline I & $1.05^{\mathrm{a}} \pm 0.03$ & $6.20^{\mathrm{c}} \pm 0.03$ \\
\hline II & $1.15^{\mathrm{a}} \pm 0.02$ & $5.23^{\mathrm{ab}} \pm 0.03$ \\
\hline III & $1.13^{\mathrm{a}} \pm 0.03$ & $5.39^{\mathrm{b}} \pm 0.03$ \\
\hline IV & $1.23^{\mathrm{b}} \pm 0.02$ & $5.08^{\mathrm{a}} \pm 0.04$ \\
\hline
\end{tabular}

Means bearing common superscripts in column do not differ significantly $(\mathrm{p}<0.05)$

\section{in broilers.}

Hence it is concluded that the combination of both Vitamin C and $O$. sanctum can combat oxidative stress caused by rapid growth rate in heat stressed broilers there by effectively enhancing the SOD, GSH-Px, catalase activities and GSH levels with concomitant decrease in lipid peroxidation levels in plasma of heat stressed broilers.

\section{References}

[1]. Siddiqui MF, M.S.Patil, K.M.Khan, L.A.Khan (2009) Sudden Death Syndrome - An Overview. Veterinary World 2(11): 444-447.

[2]. Halliwell B, J.M.C Gutteridge (2007) Free radicals in biology and medicine (4th edn). Clarendon, Oxford.

[3]. Khan RU, S Naz, Z Nikousefaut, V Tufarelli, V Laudadio (2012) Effect of ascorbic acid in heat stressed poultry. World's Poultry Science 68: 477-490.

[4]. Javanmardi J, C. Stushnoff, E. Locke, J.M.Vivanco (2003) Antioxidant activity and total phenolic content of Iranian Ocimum accessions. Food Chemistry 83:547-550.

[5]. Gupta S, PK. Mediratta, S.Singh, KK.Sharma, R.Shukla (2006) Antidiabetic, antihypercholesterolaemic and antioxidant effect of Ocimum sanctum (Linn) seed oil. Indian Journal of Experimental Biology 44: 300 - 304.

[6]. Vara Prasad Reddy L.S.S, A.Thangavel, V. Leela, K.V.S. NarayanaRaju (2009) Antioxidant enzyme status in Broilers: Role of dietary supplementation of Tulasi (Ocimum sanctum) and selenium. Tamilnadu J. Veterinary and Animal Sciences 5 (6): 251-256.

[7]. Marklund S.L, G. Marklund (1974) Involvement of superoxide anion radical in the auto oxidation of pyrogallol and a convenient assay for superoxide dismutase. Eur. J. Biochem 47: 469 - 474.

[8]. Rotruk J.T, A.L.Pope, H.E.Ganther, A.B.Swanson, D.G.Hafeman, et al. (1973) Selenium, biochemical role as a component of glutathione peroxidase purification and assay. Science 179: 588-590.

[9]. Caliborne A.L (1985) Assay of catalase. In: Handbook of Oxygen Radical Research. Ed. Greenwald R.A, CRC Press, Baco-Raton.

[10]. Moran M.S, Depierre JW, Mannervik B (1979) Levels of glutathione, glutathione reductase and glutathione-S-transferrase activities in rat lung and liver. Biochim.Biophys.Acta 582: 67-78.

[11]. Yagi K (1976) Simple fluorimetric assay for lipid peroxide in blood plasma. Biochemical Medicine 15: 212-216.

[12]. Snedecor GW, E.G. Cochran (1994) Statistical Methods. (8th edn). Iowa State University Press, USA.

[13]. Yamaguchy S (1991) The role of SOD an antioxidant. J. Natl. Cancer. Inst 28: $221-232$.

[14]. Jena B.P, N.Panda, R.C.Patra, P.K.Mishra, N.C.Behura, et al. (2013) Supplimentation of Vitamin $\mathrm{E}$ and $\mathrm{C}$ reduces oxidative stress in broiler breeder hens during summer. Food and Nutrition Sciences 4:33-37.

[15]. Chavan S, L. Sava, V. Saxena, S. Pillai, A. Sontakke, et al. (2005) Reduced glutathione: importance of specimen collection. Ind. J. Clin. Biochem 20 (1): $150-152$.

[16]. Vara Prasad Reddy L.S.S, Thangavel A, Leela V, NarayanaRaju K.V.S (2007). Effect of dietary supplementation of Tulasi (Ocimum sanctum) \& selenium on lipidperoxidation levels and growth rate in Broiler chickens. Tamilnadu Journal of Veterinary \& Animal Sciences 3(3): 144 -149.

[17]. Kurien B.J, R.H. Scofield (2006) Lipid peroxidation in systemic lupus erythematosus. Ind. J. Exp. Biol 44: 349 - 356.

[18]. Ismail Seven, Taylan Aksu, Pinar Tatli Seven, (2010) The Effects of Propolis on Biochemical Parameters and Activity of Antioxidant Enzymes in Broilers Exposed to Lead-Induced Oxidative Stress. Asian-Aust. J.Animal Science 23(11): 1482-1489. 